WellBeing International

WBI Studies Repository

2012

\title{
Sociology and Anthrozoology: Symbolic Interactionist Contributions
}

Leslie Irvine

University of Colorado Boulder

Follow this and additional works at: https://www.wellbeingintlstudiesrepository.org/acwp_habr

Part of the Animal Studies Commons, Comparative Psychology Commons, and the Other Anthropology Commons

\section{Recommended Citation}

Irvine, L. (2012). Sociology and anthrozoology: Symbolic interactionist contributions. Anthrozoos: A Multidisciplinary Journal of The Interactions of People \& Animals, 25(Supplement 1), 123-137.

This material is brought to you for free and open access by WellBeing International. It has been accepted for inclusion by an authorized administrator of the WBI Studies Repository. For more information, please contact wbisr-info@wellbeingintl.org.

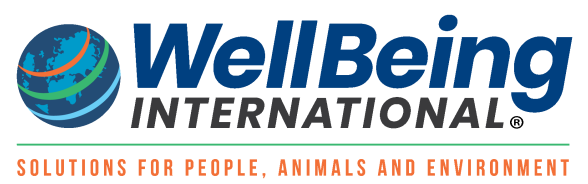




\title{
Sociology and Anthrozoology: Symbolic Interactionist Contributions
}

\author{
Leslie Irvine \\ University of Colorado at Boulder
}

\section{KEYWORDS}

animal abuse, animals, identity, symbolic interactionism, qualitative methods

\begin{abstract}
This essay examines the sociological contributions to anthrozoology, focusing on research from the United States that employs a symbolic interactionist perspective. In particular, the work of Arluke and Sanders highlights the importance of understanding the meanings that animals hold for people. Using a selective review of their research, this essay outlines how a focus on understanding meaning can inform anthrozoological research. Arluke's research on animal abuse reveals how harm must be defined in context. Sanders's research on canine-human relationships documents how people come to understand companion dogs as persons. Both bodies of work rely on careful observation and listening to those who interact with animals. The resulting insights hold methodological promise for anthrozoology.
\end{abstract}

For this twenty-fifth anniversary of Anthrozoös, I was honored to be asked to discuss the major contributions of sociology to anthrozoology. For two reasons, I have taken a highly selective, even idiosyncratic, approach to the task. First, I have limited this review to contributions of scholars from the United States. I recognize that anthrozoology is increasingly global and that European sociologists, in particular, have made significant contributions to the field. But my geographic location has shaped and situated my knowledge. In general, most American sociologists have little engagement with the scholarship originating in Europe. ${ }^{1}$ The reasons are numerous, and they potentially include methodological and theoretical bifurcations, differing political and cultural institutions, differences in the organization of academic life, and, last but certainly not least, American hegemony and parochialism. Thus, a review of the international contributions of sociology to anthrozoology is beyond my capabilities. Second, I have chosen a single perspective as the focus of this essay. I made this decision by considering the different ways one might present American sociology's contributions to anthrozoology. One logical approach would be a topical review of the literature, which would include studies of relationships with companion animals, animals as social problems, animal welfare, animal rights, and animals and work, just to name a few areas that sociologists have analyzed. Topical reviews can be useful for the scholar seeking to get a sense of the literature. But to disciplinary outsiders they risk presenting sociological contributions as a patchwork, with little or no underlying theoretical or methodological foundation that could enhance further research (see Arluke 2003). With this in mind, I have organized this essay by focusing on work employing the perspective known as symbolic interactionism. In research practice, symbolic interactionism is generally identified with qualitative methodology, especially with ethnography. Consequently, the work I examine here offers both theoretical and methodological insights for anthrozoology. 
It is not possible within the brief space of this essay to do justice to symbolic interactionism. Nevertheless, I will attempt to provide a sufficient map to guide those unfamiliar with the terrain, but not one with so much detail that readers lose sight of the destination. To lead the journey, I have chosen the work of Arnold Arluke and Clinton Sanders. They are indisputably leading figures in human-animal studies, particularly in the United States, and their interactionist approach can serve as a model for studies beyond the domain of sociology. Because of the scope and aim of this essay, some readers will be surprised and perhaps disappointed that I have not discussed work they find significant and inspiring. As mentioned, my authorial decision means that I have overlooked important and highly original research from outside the United States and outside of symbolic interactionism. Readers should not come away from this essay with the impression that interactionism is the only perspective from which sociologists conduct human-animal studies. Rather, it is my hope that after reading this essay, scholars from other disciplines will see the value of the interactionist perspective and consider building on its foundation.

In what follows, I first introduce the perspective and method of symbolic interactionism. I then discuss the omission of animals from sociology. In the course of that discussion, I explain how interactionist work has come to the fore in sociological studies of animals in the United States. I then examine two exemplary bodies of research: Sanders's work on animal identity and personhood, and Arluke's on animal abuse. In the conclusion, I discuss the promise of an interactionist-informed perspective for anthrozoology, more generally.

\section{Symbolic Interactionism: Perspective and Method}

The term "sociology" was coined by the French philosopher Auguste Comte (1798-1857). During the nineteenth and early twentieth centuries, Emile Durkheim and Max Weber helped establish departments of sociology in French and German universities. Numerous other European scholars populate the history of the discipline. But for several reasons, including the rise of fascism and two world wars fought on the European continent, during the twentieth century the United States developed a unique tradition of sociology "with its own jargon, conceptual strategies, problems, paradigms, and audience" (Seidman 1994, p. 95). In the postwar years, Marxism rose to prominence in European sociology, and structural functionalism, associated with Talcott Parsons, gained ascendancy in the United States. American scholars who sought alternatives to functionalist notions of a self-regulated, harmonious, macro-social system did not have to engage simultaneously with Marxism, which, while strong in Europe, had only a "feeble" presence in postwar American sociology (Seidman 1994, p. 127). Consequently, most of those who challenged functionalism developed micro-sociological theories rather than the theories of political economy and institutional dynamics that emerged from Europe. Symbolic interactionism was one of the leading developments. It remains a major sociological perspective, and although it originated in North America, its influence is increasingly global.

The term "symbolic interactionism" was not coined until 1937 when Herbert Blumer used it in an article on sociological social psychology, but the perspective grew from the scholarship of Blumer's teacher, philosopher George Herbert Mead, who had died six years earlier. Along with William James, John Dewey, and Charles Sanders Peirce, Mead was one of the main figures in classical American pragmatism. In the body of work he produced between 1880 and 1930, Mead portrayed "society as a pluralistic universe at the core level of which are perspectives managed by self-conscious individuals. These perspectives are structured, but the structures in question are in flux-they never cease to emerge in the here and now of situational encounters during which humans haggle over the past, present, and future" (Shalin 2000, p. 323). In this emphasis on perspectives, Mead called attention to the negotiation of meaning in the course of social life, whether that meaning be of chairs, trees, or bicycles, mothers, presidents, or priests, or justice and compassion (Blumer 1969, pp. 10-11). Rather than assuming that meanings are given or inherent, Mead maintained that we create and reproduce it in social interaction 
(Mead 1934; see also Blumer 1969, pp. 3-4). This view contrasts with the "realist" perspective, which holds that "meaning emanates, so to speak, from the thing and as such there is no process involved in its formation; all that is necessary is to recognize the meaning that is there in the thing" (Blumer 1969, p. 4). It also contrasts with the idea that meaning arises "through a coalescence of psychological elements in the person," such as "sensations, feelings, memories, motives, and attitudes" (1969, p. 4). Rather, symbolic interactionism views meaning as negotiable, "arising in the process of interaction between people" (1969, p. 4). Language—a system of symbols—provides a means to negotiate meaning, to assign names, to engage in discourse, and to build systems of knowledge. This is the sense in which interaction is symbolic. As Blumer explained, "meanings are social products, as creations that are formed in and through the defining activities of people as they interact" $(1969$, p. 5). Once meanings are derived, we use them to guide subsequent interaction. When we engage with other people, we interpret their actions instead of merely responding to them as stimulus and response. A sense of self serves as both a basis for, and consequence of, this interpretation. Mead depicted the self as a reflexive capacity to alternate between subject (the "I," or the knower) and object (the "me," or the known). The self allows us to interpret what others do and say and adjust our own actions accordingly. Blumer writes that "human life is a vast process of . . . defining to others what to do and of interpreting their definitions; through this process people come to fit their activities to one another and to form their own individual conduct" (1969, p. 10).

This brief sketch of the interactionist perspective would be incomplete without a reference to the methods that typically accompany it. Symbolic interactionism is unique for its dual role as theory and method. Its focus on the creation and negotiation of meaning and its view of human beings as actively engaged in creating the social world require methods sensitive to these processes. Thus, interactionist research typically involves immersion in situated interaction and open-ended interviews that yield an understanding of the meaning of people's actions. Bloor and Wood explain, "As symbolic interactionism developed, the research method that became most closely associated with the theory was undoubtedly ethnography. Because actors' meaning-attributions are viewed as provisional and emergent within social settings, it was clearly preferable for data on meaning-attribution to be collected in the actual settings where actors were conducting interpretive work" (2006, p. 160).

\section{Sociology and Animals}

Although I focus on symbolic interactionist-informed anthrozoological research in this essay, the perspective, and the discipline of sociology more broadly, has only recently included species other than human beings. Sociology has had a long history of anthropocentrism and consequently an uneasy relationship with animals. In attempting to create a science of society, the founders of the discipline strove to distinguish human behavior from that of animals, and in doing so, elevated human behavior to the apex. They dismissed animal behavior as based on instinct, whereas humans, in contrast, had the influence of society and culture at the helm. In this view, animal behavior simply responds to instinctual cues, but human behavior is shaped by society and culture. For example, Mead himself often used animal behavior as a foil, allowing him to extol what he considered uniquely human capacities. Chief among these capacities was spoken language. Mead maintained that although animals could communicate, they lacked the ability to do so symbolically (e.g., 1934, pp. 42-43, 238ff). ${ }^{2}$ Moreover, animal instinct left no need for interpretation. Animals thus had "no mind, no thought, and hence there is no meaning [in their behavior] in the significant or self-conscious sense" (Strauss 1964, p. 168). Any meaning we might attribute to animal behavior came from sentimental anthropomorphism, to be abandoned once we gained an understanding of animals (Mead 1934, pp. 182-183; see also Irvine 2004a, b). Lacking language, animals did not possess the quality of thought that characterized human beings. And "not being human, [animals] can in no way be social or cultural beings as this would be a 
contradiction in terms" (Noske 1989, pp. 82-83). ${ }^{3}$ With no social basis for their behavior, animals were simply not of interest to sociology's founders. Similar attitudes across the discipline ensured that animals were absent from sociological analyses. The sole known exception came from Read Bain, a contemporary of Mead's, who warned that "the persistent attempt to set human phenomena distinctly and widely apart from all other natural phenomena is a hang-over of theological teleology, an instance of organic ego-centrism, a type of wishful aggrandizement and self-glorification" that had no place in science (1928, p. 554). Bain went on to predict that the neglect of animals in sociology was "probably a phase of anthropocentrism" (p. 556).

The phase showed no signs of weakening until 1979, with the publication of an article by the late Clifton Bryant entitled "The Zoological Connection: Animal-Related Human Behavior." Sociologists, Bryant wrote, "have been singularly derelict in their failure to address the zoological component in human interaction and attendant social systems" (p. 399). This failure meant that sociologists were "myopic in their observations of human behavior, cultural patterns, and social relationships" (p. 399). He encouraged other sociologists to incorporate animals into their studies and enumerated the topics that could be enhanced by doing so. His list included the study of work and occupations, popular culture, criminology, and the sociology of the family, among many others. He pointed out that non-human animals play so many roles in society that it is difficult to imagine everyday life without them. Animal products contribute to the economy in the form of meat, eggs, dairy products, leather, wool, silk, cosmetics, soap, toiletries, and medications. They surround us in our homes and offices, in the form of drywall, linoleum, paint, and adhesive for wallpaper and carpet. Our language incorporates countless animal influences. A person can wear a "pony tail, have "buck teeth," and be "pig-headed," "gentle as a lamb," or "strong as an ox" (see also Smith-Harris 2004). In addition, animals have assisted people in many ways throughout history. They have plowed fields, served as transportation, and helped us wage war. Today, they not only help people see and hear, they predict seizures and even detect the subtle presence of undiagnosed cancer. Animals figure heavily in phenomena considered social problems, such as dog fighting and gang violence. Bryant concluded by saying that sociologists would "be well advised to add animals to the lexicon of our discipline" (p. 417). To reach a full understanding of "human social behavior in all its vagaries," he wrote, "and to be completely sensitive to the full array of its nuisances and subtleties, we must enhance our appreciation of its zoological dimension" (p. 417).

Arnold Arluke and Clinton Sanders were among the first American sociologists to take Bryant's admonition to heart. ${ }^{4}$ In the 1980s, Arluke began investigating the use of animals in research laboratories. Through ethnographic research, he examined how scientists construe the meaning of the animals they use in experiments and come to terms with the controversial nature of animal studies. He went on to study animal shelter workers, humane law enforcement agents, veterinary students, and animal hoarders, focusing on how they understood animals within these contexts. Around the same time, Sanders focused on relationships with companion dogs, particularly on how their interaction with human caretakers challenged Mead's assumption that meaningful communication does not exist among animals. In contrast to Mead, with his perspective of "no mind, no thought, no meaning," Sanders presented dogs as "unique individuals who are minded, empathetic, reciprocating, and well aware of basic rules and roles that govern the relationship" they have with their human caretakers (1993, p. 207). Steven and Janet Alger (1997, 1999, 2003a) extended this line of research into human-feline interaction and eventually into interactions among cats. Clifton Flynn (1999a, b, 2000a, b, c; 2001) began exploring the relationship between animal abuse and family violence, taking a feminist interactionist perspective on the roles of animals in the lives of battered women. By 2002, a sufficient number of scholars worked in the area that the American Sociological Association officially recognized a section on Animals and Society. This occurred despite the objections of some who disparaged the study of animals as "boutique" sociology (e.g., Perrow 2000; see Nibert 2003). The Section remains small relative to other interest areas within 
sociology, but it has grown steadily over the years. In my view, its survival depends largely on graduate students who have the courage to challenge the field's outdated ideas about animals. Two examples will make my point. In 2008 and 2009, I wrote letters of recommendation for a student seeking a job as an academic sociologist. I was not the student's advisor, but I had served on her dissertation committee. This particular student had not secured a job in 2008 and thus was back on the market the following year, at which time she provided me with an updated version of her curriculum vitae. Although her dissertation research was in another area, she had published an original anthrozoological study in the course of her graduate work. In the 2008 version of her C.V., she listed "Animals and Society" as one of her research interests. In the 2009 version, she had removed it from the list. I asked why. She explained that her advisor thought it might have been the reason she did not get a job the previous year. My colleague thought that listing "Animals and Society" as an interest area made the student appear less than serious as a scholar. The student did land a job the second year. Whether it was a matter of timing or the result of presenting a more "serious" scholarly image, I will never know.

To offer another example, a study by Alger and Alger examined the depictions of animals in 30 major introductory sociology textbooks (2003b). The Algers focused on whether and how well the texts integrated research on animals conducted over the preceding 20 years. Their analysis revealed that most of the textbooks ignored this research altogether. A notable example is the treatment of the topic of "culture," considered so essential in sociology that all introductory texts have a chapter or large section devoted to it. The Algers wrote:

All of the authors defined human culture in essentially the same way. Culture is a "design or blueprint for living," a "way of life," or a "social heritage." Culture is learned, it is shared, and it is passed on to the next generation. The elements of culture offered by these authors were also very similar and included beliefs, values, norms, symbols, language, customs, technology, knowledge and material objects. And, the tremendous diversity of cultures among different human groupings constituted the evidence that culture is a human creation, and not biologically determined. When these same authors turned their attention to the question of animals and culture, however, several problems immediately became apparent. (p. 72)

In their review, the Algers found that textbook authors routinely ignored evidence of culture among other species and asserted its absence without citing any references. Authors seemed to assume that "their views on animal culture were so well established that no source was necessary or that comments about animals were not of sufficient importance to warrant serious research" (p. 72). They ignored contemporaneous research that found culture among cats (Alger and Alger 1999, 2003b), chimpanzees (Goodall 1986; Dawkins 1998; Whiten et al. 1999), and parrots (Pepperberg 1991). In addition, they ignored important evidence of the existence of culture long before our hominid ancestors split off the evolutionary path from chimpanzees (Van Schaik, Deaner and Merrill 1999; Van Schaik et al. 2003). Although the inclusion of animals could enhance the understanding of culture, the research that documents culture among animals is routinely omitted from the texts that typically provide students with their first taste of sociology. The few texts that granted the possibility of culture among other animals took pains to elevate human achievements. For example, although one text allowed that "humans are not unique just because they make and use tools," the authors added that "the tools that humans make are unequaled in complexity. Think of the difference between using a twig to catch termites and making an automobile" ([Andersen and Taylor 2002, p. 63] Alger and Alger 2003b, p. 75). Thus, even when authors did recognize animals' capacities, "it was necessary to have high culture to be considered as having a culture worthy of the name" (Alger and Alger 2003b, p. 75). From an anthrozoological perspective, one 
can hope that the next generation of scholars will incorporate research on animals into the introductory textbooks.

The issue of the insights animals hold for sociological texts makes two important points with which to conclude this discussion of the discipline. First, sociology remains anthropocentric even while humananimal studies have gained traction within it. Sociology is defined as the study of human society. Many sociologists have expertise and interest in animal behavior in its own right, but our intellectual task is to understand human behavior. For sociologists, animals are "windows for understanding ourselves. They reveal our most essential conceptions of the social order-how we think things should ideally be or not be-while unmasking our expectations, hopes, fears, and hatreds of fellow humans and modern life" (Arluke 2010a, p. 35). Second, sociologists who study animals have made contributions that not only shed light on key sociological issues but also have implications that extend beyond the discipline's intellectual boundaries. I turn now to examples of research that accomplishes both of these tasks.

\section{Theorizing Identity and Personhood in Animals}

The research by Clinton Sanders examines relationships between humans and non-human animals to illuminate the identities of both. Informed by the symbolic interactionist perspective, Sanders depicts animals as minded participants in social life. He has detailed how interaction brings the identities of canine companions into being (1990, 1991, 1993, 1994a,b, 1995, 1999, 2000, 2003, 2006; Robins, Sanders and Cahill 1991). In any interaction, identity is considered a necessary component of relationships because it "establishes what and where the person is in social terms" (Stone 1981, p. 188). Once we know how a person defines him or herself, and we situate him or her in social groups such as age or gender, we have a basis for interaction. Then, we can begin to know them as individuals. With other people, we have the benefit of language to help us sort out identities. With animals, the absence of a shared language changes how we gain this information. Sanders took on the challenge of understanding how we accomplish this by talking to people about their relationships with their dogsmore accurately, by listening to them. He also observed them in several settings and recorded observations of his relationships with his own canine companions. He noted that most people refer to their dogs as "persons," in one way or another. He took this seriously rather than dismissing it as anthropomorphism, and he set out to examine what it meant. In other words, he sought to learn how people understood their interactions with their dogs. His intention comes through in this passage from Understanding Dogs, where he wrote that, to capture the role of animals in our lives, "it is necessary to examine closely the real experiences and listen carefully to the words of those who love, educate, depend upon, and care for the nonhuman members of our society" (1999, p. 15).

Through this close examination and careful listening, Sanders found that the process of assigning identity to dogs works in much the same way as it does with humans. We begin by taking into account what is known as "categorical identity" (Cahill 1998, p. 136). With other people, we might assign gender, race, ethnicity, and age. With animals, we begin with species. We draw on popular cultural stereotypes, such as "dogs are loyal," and "cats are independent." With dogs, we then use breed characteristics, such as "Dalmatians are 'unpredictable,' terriers are 'high strung and energetic'...'You have to be strong with a Malamute"' (Sanders 2003, p. 410). Then, we go on to assign individual characteristics to particular dogs. We begin to see the dog "as much more than a species or breed representative" (p. 410). We often see them as exceptions to the rule. We see personality traits and preferences. And, as Sanders shows, the identities of animals shape the identities of their caretakers. This is particularly the case with dogs because they so frequently appear with people in public. When appearing together, other people consider the human and the dog as a unit. They assign an identity to the person based on the identity they attribute to the dog, which they establish in the process outlined above, beginning with breed characteristics. Thus, observers give a person walking a toy poodle an identity that differs from the 
identity they give a person walking a Labrador retriever. But this shared identity also means that caretakers' identities can suffer when their dogs behave inappropriately. Sanders explains, "As the most 'responsible' member of the human-animal couple, everyone expects the person to control the animal. Consequently, when the animal bites, fails to 'mind' the caretaker, jumps on strangers, or in other ways breaches the boundaries of 'appropriate' public behavior, the caretaker's identity suffers" (2003, p. 413). To account for their dogs' behavior and minimize the negative impact on their own identities, people use what Sanders (1990) describes as "excusing tactics." Choice of tactic varies depending on situation, damage incurred, age of dog, and other factors, and they include statements such as "He gets really nervous when you touch him there," "She's just a puppy," or "He just thinks he's tough."

A notable part of identity construction in companion animals occurs when we call them by name. This is one of the most effective ways of distinguishing an animal as an individual. Its importance is apparent in settings in which animals are not named (Phillips 1994). In contrast to the environment in which the dog or cat is considered a member of the family, these are mostly instances in which animals serve as tools. For example, animals used in research or food production are typically given numbers rather than names, so that individuality does not hamper the goal of the animals' eventual death. With companion animals, however, individual characteristics or behavioral tendencies often influence the choice of name. Indeed, as Sanders points out, people routinely give dogs human names, "symbolically casting him or her in the role of virtual person with uniquely individual characteristics" $(2003$, p. 411$){ }^{5}$

The notion of virtual personhood is an important part of human-canine interaction, partly because it makes relationships with animals qualitatively different from those we have with people. Sanders draws on work among other non-verbal populations such as the severely disabled to point out that personhood "is constructed and shared through interaction," and thus can pertain to dogs in relationship with people (2003, p. 419; see also Bogdan and Taylor 1989, p. 136). As he explains:

The animal is a person in the sense that his or her perspective and feelings are knowable; interaction is predictable; and the shared relationship provides an experience of closeness, warmth, and pleasure. In an important way, the distinction between relationships with humans and with animal-persons is central to the special character of the human-animal bond. Because they are not human relationships, those with companion animals are constant rather than contingent. The animal's response to his or her companion does not depend on the latter's appearance, age, economic fortunes, abilities, or the other vagaries that, for good or ill, constrain human-to-human relationships. (2003, p. 418)

By studying how we define dogs as "persons," Sanders sheds light on how we integrate them into relationships, whether as family members or close friends. His research reveals that people see dogs as "unique, communicative, emotional, reciprocating, and companionable being[s]" (1999, p. 10). Dogs demonstrate the ability to share intentions, feelings, and other mental states with their human companions, and we thus come to know them as conscious, purposeful partners in interaction.

Through close observation and careful listening, Sanders showed that our attributions of animals' sense of themselves are not simply wishful anthropomorphism. He revealed that although we humans can put our accounts of who we are into words, identity itself does not depend on language. He consequently opened the door for research that takes relationships with animals seriously as an empirical topic, and a sizeable body of sociological literature has grown from the foundation he established (e.g., Irvine 2004a,b; Brandt 2004, 2005, 2006; Ellis 2011). I discuss how his perspective can inform anthrozoology after examining the work of Arnold Arluke. 


\section{Clarifying the Relationship between Animal Abuse and Other Forms of Violence}

The sociological research on violence toward animals sheds light on an issue of considerable anthrozoological interest: the connection between the abuse of animals and violent behavior toward other people. In general, the sociological research challenges the assumption that animal abuse is an indication of individual psychopathology (see Arluke et al. 1999; Arluke 2002, 2006; Piper 2003; Beirne 2004). It also maintains that the relationship between animal abuse and other forms of violence may be less direct and more complex than it often appears.

Historically, much of the research on animal abusers has been done by psychologists and animal welfare advocates. It generally assumes what is known as the "graduation hypothesis," popularly referred to as "the link." This is the idea that violent criminals start their misdeeds on animals and then progress to human-directed acts. ${ }^{6}$ The idea originated in a 1963 article in which forensic psychiatrist John M. MacDonald listed animal abuse as one of three warning signs of sociopathic behavior, along with bedwetting and fire setting. Although research has since challenged this triad-MacDonald himself could not support it empirically - the idea of a path from animal abuse to violence toward humans remains firmly established in the public and the criminological imaginations. This is understandable, for it serves important ideological functions. Following a particularly violent crime, the media often report that the perpetrator had a history of abusing animals. Investigators and the public alike find it reassuring to believe that warning signs had forecasted the unimaginable behavior. In addition, animal welfare advocates rely on the link when crimes against animals would otherwise go unpunished. Thus, any research that questions the idea of a progression from animal abuse to other forms of violence challenges a significant sacred cow.

Research by Arluke has offered the most enduring challenge, as well as a consistent reminder that "the meaning of harming animals [cannot] be independently arrived at and imposed apart from real-world situations where it occurs" (2006, p. 5). Informed by the interactionist perspective, Arluke emphasizes the need to examine how acts of cruelty are defined in the context in which they occur and to understand what such acts mean for those who engage in them. For example, in research among college students, Arluke found that approximately $20 \%$ admitted to having harmed or killed animals as children or adolescents (none had been arrested for their acts) (2002, 2004a, 2006). This alone is not new; other studies have found results ranging from 14 to $35 \%$, and students tend to under-report rather than overreport acts of cruelty, even in anonymous surveys (Miller and Knutson 1997; Flynn 1999a; Henry 2004; Lea 2007). What Arluke brought to the conversation was an understanding of the significance these acts had for the students and what their behavior meant in the context of adolescent socialization. Several elements of their experience pointed to the degree to which students defined their actions as play, not abuse. First, he found that many of them recalled acts of abuse as just another activity, or just something kids did when they had nothing else to do. Second, they compared their abusive actions to other forms of play, such as skateboarding, basketball, or Nintendo. Third, they did not recall violent or otherwise explosive emotions directing their acts; they had expressed no intention to inflict harm or to kill animals. And fourth, they kept their acts within limits. They talked about only wanting to toy with the animals, for example, and emphasized that they did not try to kill them. As one student said "he did not 'think about hurting' a rabbit when he and his friend shot it with a BB gun. Instead, the two of them focused on seeing the rabbit 'flip"' (2006, p. 63). As the interviews continued, the students recognized that their behavior had "a serious edge that distinguished it from everyday play in general or normal play with animals" (2006, p. 62). Their cruelty fit a category known as "dirty play" (Fine 1986), which functions as a rite of passage into adult behaviors. Dirty play can include "aggressive pranks, sexual talk, and racist remarks" or more deviant acts such as harming animals (Arluke 2002, p. 408). Especially when engaged in with peers, dirty 
play instructs kids in adult-like knowledge such as keeping secrets and establishing boundaries. As Arluke explains, seen as dirty play, abuse is one way that children appropriate adult culture:

Respondents remembered their untoward acts toward animals as cool and thrilling because these are part of the process of interpretive reproduction . . . whereby children usurp adult information to address their own confusions, fears, and uncertainties, including those relating to their transition out of adolescence into adulthood. (2006, p. 64)

Arluke found that as children mature and their identities change, they stop thinking of dirty play as fun. Years later, during interviews, the students indicated that they had left the behavior-and the adolescent selves that had enacted it-in the past. Rather than being a sign of psychopathology, the period during which some children's play included abusing animals "may have been more of a cultural 'time out' than a lasting sign of incivility or anti-social behavior" (2006, p. 78). Some students felt guilty about having harmed animals, but others laughed when they recalled their acts. Arluke points out that this is evidence of the ambivalence toward animals that is characteristic of modern Western societies (see also Arluke and Sanders 1996). Animal researchers, for example, "tout their love and admiration for animals, especially their own pets, while carrying out experiments on the same species" (2002, p. 427; see also Arluke 1988). "Slapstick portrayals of animal suffering [are] common in mainstream popular culture," he writes. "Such humorous slants on cruelty are plentiful and can be seen in children's stories, cartoons, and comics, as well as in adult advertising, movies, and even occasional talkradio programs, that have long been known to make light of animals being harmed or even killed" (2002, p. 427; see also Solot and Arluke 1997). The popular video game "Angry Birds" involves flinging birds at stacks of planks and bricks in an attempt to kill "evil" pigs. In short, that some students could still be entertained by their acts reflects not psychopathology but a culture deeply divided on the moral status of animals.

As abhorrent as animal abuse is to most of us, Arluke's research demonstrates that it has a social function and it must be considered in context. Many actions conducted in the research laboratory or the slaughterhouse would be considered cruelty outside of those settings. As Arluke points out, "many different groups-however they define or approach cruelty-use it to build or frame their identities in positive ways" (2006, p. 8). Whether one conducts abuse or confronts it, has an impact on identity, but that impact may not necessarily take the form of psychopathology. Understanding what forms it takes requires watching and listening without an ideological agenda.

\section{Conclusion}

As mentioned, the work of Arluke and Sanders has been enormously influential in sociological studies of human-animal interaction. Many scholars outside of sociology have also drawn on their insights. My brief review does not do justice to their work as a whole, but my goal in this essay is to use a glimpse of it to enlarge the pool of those who recognize the substantial promise interactionism holds for anthrozoology, more generally. In drawing this essay to a close, I refer to Arluke and Sanders's work to highlight potential avenues of application. I also offer suggestions for how non-sociologists might draw from interactionist insights.

Although the research by Arluke and Sanders examines different topics, it shares a common theme that can inform many studies in anthrozoology. Simply put, humans and animals co-exist within relationships to which we attach meaning. Whereas the research by Sanders yields insights into relationships that are of a compassionate nature, Arluke's work sheds light on the dynamics when relationships involve cruelty. For both scholars, understanding the meaning-making that occurs in these contexts has involved careful listening and observation without imposing prefabricated definitions. Many anthrozoological studies, especially those within psychology, involve concepts whose meaning is far from settled when viewed with 
an interactionist perspective. Yet, this research often takes for granted what it sets out to examine. For example, significant anthrozoological research explores attachment to animals, particularly those used as companions. An article in the first issue of Anthrozoös measured pet attachment among urban dwellers (Albert and Bulcroft 1987), and at least 49 subsequent articles used the term "attachment" in the title, abstract, or keywords. An informal review of these articles suggests that most assume that attachment to animals is beneficial for humans on its own, and, in addition, that it may be linked to prosocial behavior (e.g., Thompson and Gullone 2008). Likewise, empathy, has received much attention. In an early issue of Anthrozoös, Eisenberg (1988) noted that there was 'relatively little research concerning humans' empathy for animals" (p. 15). But in ensuing years, over thirty articles appeared in the journal with "empathy" in the title, abstract, or keywords. Many of these used scales or other tools to measure or assess empathy, with a particular focus on whether and how empathy for animals makes people more empathetic toward other human beings.

This body of research raises questions about meaning that an interactionist approach can illuminate. When examining topics such as empathy or attachment, an interactionist would ask what these concepts mean for those participating in the research. For example, rather than beginning with a definition of animal abuse, Arluke's research asked how people who admit to having harmed animals understood their actions, both at the time and in retrospect. Likewise, Sanders's work examines how it is that people come to understand their dogs as persons. This approach points to a different set of questions than those embedded in the extant research on empathy and attachment. Much of the work on these topics comes from psychology, and agreement about a concept such as empathy seems to be reached when there is statistical reliability and validity in its measures. Thus, a Cronbach's alpha, Pearson product-moment correlation, or other statistical indicator is enough to suggest that concepts such as empathy or attachment have been successfully captured. But what is empathy, really? Does sleeping near one's animal really indicate attachment? And what does it mean to "sleep near" one's animal? What does doing the bulk of the work associated with the care of a companion animal necessarily mean about the relationship, apart from having a close correlation with other items on a scale? The meaning of these actions might be very different from what the correlation suggests. Of course, one could say that if we asked such questions about the meaning of everything we would never get anywhere with the research. I take the point. But precisely because much of this research promises to reveal connections between the concepts it measures and pro-social behavior, clarifying the basic meaning of the concepts is essential for doing solid follow-on research. Learning what promotes pro-social behavior is an important goal, but without fully understanding the meaning of what might do so, one can never really be sure of the relationship. Interactionist research on how people understand empathy and attachment would give both breadth and depth to the discussion.

Another topic that receives considerable anthrozoological attention is the potential benefit of humananimal relationships for the people who engage in them. This research examines the effects of petkeeping as well as the interventions aimed at improving human psychological and physical health. In the "interventions" category, I include the many activities and therapies—both structured and recreationaldesignated as "animal-assisted." One of the most cited papers on the benefits of animals for human health is the 1980 study of heart attack victims by Friedman et al. Twenty-eight percent of those who had pets survived for at least a year, compared with only $6 \%$ of non-pet owners. Research on the benefits of pet ownership for human health has flourished in the ensuing years, examining the impact of animals on blood pressure, depression, stress, and other states. But as Herzog has recently reported, the research on what he calls "the pet effect" is inconclusive at best, and the media tend to ignore disconfirming results (2011). For example, few people will have heard of the study that found that pet owners were more likely than non-pet owners to die within a year of a heart attack (22\% compared with 14\%; Parker et al. 2010). Similarly, studies such as the one that found that pet owners suffered more from psychological problems 
such as anxiety, insomnia, and depression, than those who did not own pets receive little if any attention in the media (Mullersdorf et al. 2010). Along with the tendency to publish only positive results, design problems often lead to conflicting results. In addition, much of the extant work is done by those who have an interest in documenting a benefit from such involvements.

A perspective that asks about the meaning animals hold for people in various settings can provide an essential starting point for research on the purported benefits that animals provide. Research needs to uncover and specify what kinds and qualities of relationships with animals provide benefits. Doing so requires exploring how those within such programs understand animals. This obviously includes participants, but goes beyond, to include the ideological underpinnings of the programs and those who run them. ${ }^{7}$ Once again, this kind of exploration requires careful listening and observation. The results can eliminate or at least minimize the bias toward benefits and instead capture where any benefits come from.

Researchers schooled in using established scales and measures may find it far-fetched to question meaning. Indeed, it is not my intention to suggest that all anthrozoologists become full-fledged symbolic interactionists. Rather, I argue that those who seek objectivity in their research would benefit from the reminder that animals are not experienced in the same way by all persons or groups. Standardized, mainstream methods simply frame the dominant ways of thinking about animals; they are often inadequate for advancing knowledge. A better understanding of the meanings animals hold for people can lead to definitions and measures that are grounded in lived realities. In other words, a commitment to understanding meaning can maximize objectivity. Whatever ways one approaches the task, anthrozoologists can only benefit from rigorous examination of the meaning that lies at the heart of the questions that pique our interest.

\section{Notes}

1. There are certainly exceptions to this. In addition, an anonymous reviewer for this journal informed me that the reverse was not true. Scholars in Europe are familiar with the American research.

2. I have noted that Mead developed this mechanistic view of animals despite having had a dog as a companion, especially during his years at the University of Chicago (Irvine 2003).

3. See Myers (2003) and Irvine (2004a, b) for correctives to Mead's view.

4. For ease of reading, I have not listed the extensive in-text citations for Arluke and Sanders. Their works appear in the references.

5. In my research on adoption of animals from shelters, I found that people who acquire a dog or cat with a name they deem unsuitable change it to one that seems a better match for the animal's identity, as they know it (Irvine 2004a, p. 135).

6. Arluke et al. (1999) distinguish a strong form and a general form of the "graduation hypothesis." In the strong form, "violence toward animals comes first and is subsequently generalized toward humans" ( $p$. 964). In the general form, cruelty to animals is one of 15 signs of Conduct Disorder, as listed in the Diagnostic an Statistical Manual of Mental Disorders.

7. See Arluke (2010b) for a study that takes this approach. 


\section{References}

Albert, A. and Bulcroft, K. 1987. Pets and urban life. Anthrozoös 1: 9-25.

Alger, J. M. and Alger, S. F. 1997. Beyond Mead: Symbolic interaction between humans and felines. Society \& Animals 7: 199-218.

Alger, J. M. and Alger, S. F. 1999. Cat culture, human culture: An ethnographic study of a cat shelter. Society \& Animals 7: 199-218.

Alger, J. M. and Alger, S. F. 2003a. Cat Culture: The Social World of a Cat Shelter. Philadelphia: Temple University Press.

Alger, J. M. and Alger, S. F. 2003b. Drawing the line between humans and animals: An examination of introductory sociology textbooks. International Journal of Sociology and Social Policy 23: 69-93.

Andersen, M. L. and Taylor, H. F. 2002. Sociology: Understanding a Diverse Society. 2nd edn. Belmont, CA: Wadsworth/Thompson Learning.

Arluke, A. 1987. Reasons for sociological study of animal research: The experimenter as guinea pig. Bulletin of Psychologists for the Ethical Treatment of Animals 6: 8-9.

Arluke, A. 1988. Sacrificial symbolism in animal experimentation: Object or pet? Anthrozoös 2: 98-117.

Arluke, A. 1989. Living with contradictions. Anthrozoös 3: 90-99.

Arluke, A. 1990a. From an animal's point of view. Behavioral and Brain Sciences 13: 13-14.

Arluke, A. 1990b. The individualization of laboratory animals. Humane Innovations and Alternatives in animal Experimentation 4: 199-201.

Arluke, A. 1990c. The ethical thinking of animal researchers. New Biologist 3: 1-2.

Arluke, A. 1990d. Uneasiness among laboratory technicians. Lab Animal 19: 20-39.

Arluke, A. 1991. Going into the closet with science: Information control among animal experimenters. Journal of Contemporary Ethnography 20: 306-330.

Arluke, A. 1992. Trapped in a guilt cage. The New Scientist 134: 33-35.

Arluke, A. 1993. Bringing animals into social scientific research. Society \& Animals 1: 5-7.

Arluke, A. 1994a. "We build a better beagle": Fantastic creatures in lab animal ads. Qualitative Sociology 17: 143-158.

Arluke, A. 1994b. The ethical socialization of animal researchers. Lab Animal 23: 30-35.

Arluke, A. 2002. Animal abuse as dirty play. Symbolic Interaction 25: 405-430.

Arluke, A. 2003. Ethnozoology and the future of sociology. International Journal of Sociology and Social Policy 23: 26-45.

Arluke, A. 2004a. Brute Force: Animal Police and the Challenge of Cruelty. West Lafayette, IN: Purdue University Press. 
Arluke, A. 2004b. The use of dogs in medical and veterinary training: Understanding and approaching student uneasiness. Journal of Applied Animal Welfare Science 7: 197-204.

Arluke, A. 2006. Just a Dog: Understanding Animal Cruelty and Ourselves. Philadelphia: Temple University Press.

Arluke, A. 2010a. Our animals, ourselves. Contexts 9: 34-39.

Arluke, A. 2010b. Animal-assisted activity as a social experience. In Handbook on Animal-Assisted Therapy, 401-419, ed. A. Fine. London: Academic Press.

Arluke, A. and Hafferty, F. 1996. From apprehension to fascination with "dog lab": The use of absolutions by medical students. Journal of Contemporary Ethnography 25: 201-225.

Arluke, A., Levin, J., Luke, C. and Ascione, F. 1999. The relationship between animal abuse to violence and other forms of antisocial behavior. Journal of Interpersonal Violence 14: 245-253.

Arluke, A. and Lockwood, R. 1997. Understanding cruelty to animals. Society \& Animals 5: 183-193.

Bain, R. 1928. The culture of canines. Sociology and Social Research July-August: 545-556.

Bierne, P. 2004. From animal abuse to interhuman violence? A critical review of the progression thesis. Society \& Animals 12: 39-65.

Bloor, M. and Wood, F. 2006. Key Words in Qualitative Methods: A Vocabulary of Research Methods. London: Sage.

Blumer, H. 1937. Social psychology. In Man and Society: A Substantive Introduction to the Social Science, 144-198, ed. E. P. Schmidt. New York: Prentice-Hall.

Blumer, H. 1969. Symbolic Interactionism. Englewood Cliffs, NJ: Prentice-Hall.

Bogdan, R. and Taylor, S. 1989. Relationships with severely disabled people: The social construction of humanness. Social Problems 36: 135-148.

Brandt, K. 2004. A language of their own: An interactionist approach to human-horse communication. Society \& Animals 12: 299-316.

Brandt, K. 2005. Intelligent bodies: Women's embodiment and subjectivity in the human-horse communication process. PhD thesis, University of Colorado at Boulder.

Brandt, K. 2006. Intelligent bodies: Embodied subjectivity human-horse communication. In Body/Embodiment: Symbolic Interaction and the Sociology of the Body, 141-152, ed. D. Waskul and P. Vannini. Burlington, VT: Ashgate.

Bryant, C. D. 1979. The zoological connection: Animal-related human behavior. Social Forces 58: 399421.

Cahill, S. 1998. Toward a sociology of the person. Sociological Theory 16: 131-148.

Dawkins, M. S. 1998. Through Our Eyes Only? The Search for Animal Consciousness. Oxford: Oxford University Press. 
Eisenberg, N. 1988. Empathy and sympathy: A brief review of the concepts and empirical literature. Anthrozoös 2: 15-17.

Ellis, C. 2011. Breeding inequality: Human-animal relationships in beef production. PhD thesis, University of Colorado at Boulder.

Fine, G. A. 1986. The dirty play of little boys. Society 24: 63-67.

Flynn, C. P. 1999a. Animal abuse in childhood and later support for interpersonal violence in families. Society \& Animals 7: 161-172.

Flynn, C. P. 1999b. Exploring the link between corporal punishment and children's cruelty to animals. Journal of Marriage and the Family 61: 971-981.

Flynn, C. P. 2000a. Why family professionals can no longer ignore violence toward animals. Family Relations 49: 87-95.

Flynn, C. P. 2000b. Woman's best friend: Pet abuse and the role of companion animals in the lives of battered women. Violence Against Women 6: 162-177.

Flynn, C. P. 2000c. Battered women and their animal companions: Symbolic interaction between human and non-human animals. Society \& Animals 8: 99-127.

Flynn, C. P. 2001. Acknowledging the "zoological connection": A sociological analysis of animal cruelty. Society \& Animals 9: 71-87.

Friedmann, E., Katcher, A. H., Lynch, J. J. and Thomas, S. A. 1980. Animal companions and one-year survival of patients after discharge from a coronary care unit. Public Health Reports 95: 307-312.

Goodall, J. 1986. The Chimpanzees of Gombe: Patterns of Behavior. Cambridge, MA: Belknap Press.

Henry, B. C. 2004. The relationship between animal cruelty, delinquency, and attitudes toward the treatment of animals. Society \& Animals 12: 185-207.

Herzog, H. 2011. The impact of pets on human health and psychological well-being: Fact, fiction, or hypothesis? Current Directions in Psychological Science 20: 236-239.

Irvine, L. 2003. George's bulldog: What Mead's canine companion could have told him about the self. Sociological Origins 3: 46-49.

Irvine, L. 2004a. If You Tame Me: Understanding our Connection with Animals. Philadelphia: Temple University Press.

Irvine, L. 2004b. A model of animal selfhood: Expanding interactionist possibilities. Symbolic Interaction 27: 3-21.

Irvine, L. 2007. The question of animal selves: Implications for sociological knowledge and practice. Qualitative Sociology Review 3: 5-21.

Lea, S. R. G. 2007. Delinquency and Animal Cruelty: Myths and Realities about Social Pathology. New York: LFB Scholarly Press.

Macdonald, J. M. 1963. The threat to kill. American Journal of Psychiatry 120: 125-130. 
Mead, G. H. 1934. Mind, Self and Society. Chicago: University of Chicago Press.

Miller, K. S. and Knutson, J. F. 1997. Reports of severe physical punishment and exposure to animal cruelty by inmates convicted of felonies and university students. Child Abuse and Neglect 21: 5982.

Müllersdorf, M., Granström, F., Sahlqvist, L. and Tillgren, P. 2010. Aspects of health, physical/leisure activities, work and sociodemographics associated with pet ownership in Sweden. Scandinavian Journal of Public Health 38: 53-63.

Myers, O. E., Jr. 2003. No longer the lonely species: A post-Mead perspective on animals and sociology. International Journal of Sociology and Social Policy 23: 46-68.

Nibert, D. 2003. Origins of the ASA section on animals and society, with a bibliographic appendix. Sociological Origins 3: 53-58.

Noske, B. 1989. Humans and Other Animals. London: Pluto.

Parker, G. B., Gayed, A., Owen, C. A., Hyett, M. P., Hilton, T. M. and Heruc, G. A. 2010. Survival following an acute coronary syndrome: A pet theory put to the test. Acta Psychiatrica Scandinavica 121: 65-70.

Pepperberg, I. 1991. A communicative approach to animal cognition: A study of conceptual abilities of an African Grey parrot. In Cognitive Ethology: The Minds of Other Animals, 153-186, ed. C. A. Ristau. Hillsdale, NJ: Lawrence Erlbaum.

Perrow, C. 2000. An organizational analysis of organizational theory. Contemporary Sociology 29: 460476.

Phillips, M. 1994. Proper names and the social construction of biography: The negative case of laboratory animals. Qualitative Sociology 17: 119-142.

Piper, H. 2003. The linkage of animal abuse with interpersonal violence: A sheep in wolves' clothing? Journal of Social Work 3: 161-177.

Robins, D. M., Sanders, C. R. and Cahill, S. E. 1991. Dogs and their people: Pet-facilitated interaction in a public setting. Journal of Contemporary Ethnography 20: 3-25.

Sanders, C. R. 1990. Excusing tactics: Social responses to the public misbehavior of companion animals. Anthrozoös 4: 82-90.

Sanders, C. R. 1991. The animal "other:" Self-definition, social identity, and companion animals. In Advances in Consumer Research, Vol. 17, 662-668, ed. M. E. Goldberg, G. Gorn and R. W. Pollay. Provo, UT: Association for Consumer Research.

Sanders, C. R. 1993. Understanding dogs: Caretakers' attributions of mindedness in canine-human r elationships. Journal of Contemporary Ethnography 22: 205-226.

Sanders, C. R. 1994a. Annoying owners: Routine interactions with problematic clients in a general veterinary practice. Qualitative Sociology 17: 159-170.

Sanders, C. R. 1994b. Biting the hand that heals you: Encounters with problematic patients in a general veterinary practice. Society \& Animals 2: 47-66. 
Sanders, C. R. 1995. Killing with kindness: Veterinary euthanasia and the social construction of personhood. Sociological Forum 10: 195-214.

Sanders, C. R. 1999. Understanding Dogs: Living and Working with Canine Companions. Philadelphia: Temple University Press.

Sanders, C. R. 2000. The impact of guide dogs on the identity of people with visual impairments. Anthrozoös 13: 131-139.

Sanders, C. R. 2003. Actions speak louder than words: Close relationships between humans and nonhuman animals. Symbolic Interaction 26: 405-426.

Sanders, C. R. 2006. The dog you deserve: Ambivalence in the k-9 officer/patrol dog relationship. Journal of Contemporary Ethnography 35: 148-172.

Seidman, S. 1994. Contested Knowledge: Social Theory in the Postmodern Era. Malden, MA: Blackwell.

Shalin, D. N. 2000. George Herbert Mead. In The Blackwell Companion to Major Social Theorists, 302344, ed. G. Ritzer. Malden, MA: Blackwell.

Smith-Harris, T. 2004. There's not enough room to swing a dead cat and there's no use flogging a dead horse. ReVision 27: 12-15.

Solot, D. and Arluke, A. 1997. Learning the scientist's role: Animal dissection in middle school. Journal of Contemporary Ethnography 26: 28-54.

Stone, G. 1981. Appearance and the self: A slightly revised version. In Social Psychology through Symbolic Interaction, 2nd edn, 187-202, ed. G. Stone and H. Farberman. New York: John Wiley.

Strauss, A. ed. 1964. George Herbert Mead on Social Psychology. Chicago: University of Chicago Press.

Thompson, K. L. and Gullone, E. 2008. Prosocial and antisocial behaviors in adolescents: An investigation into associations with attachment and empathy. Anthrozoös 21: 123-137.

Van Schaik, C., Ancrenaz, M., Borgen, G., Galdikas, B., Knott, C. D., Singleton, I, Suzuki, A., Utami, S. S. and Merrill, M. 2003. Orangutan cultures and the evolution of material culture. Science 299: 102105.

Van Schaik, C., Deaner, R. O. and Merrill, M. Y. 1999. The conditions for tool use in primates: Implications for the evolution of material culture. Journal of Human Evolution 36: 719-741.

Whiten, A., Goodall, J., McGrew, W. C., Nishida, T., Reynolds, V., Sugiyama, Y., Tutin, C. E. G., Wrangham, R. W. and Boesch, C. 1999. Cultures in chimpanzees. Nature 399: 682-685. 